\title{
Improving Student Retention Through a Redesigned First-Year Engineering Class
}

\section{Dr. Jonathan Backens, Christopher Newport University}

Jonathan Backens is an assistant professor of electrical engineering at Christopher Newport University (CNU). He received his Ph.D. in electrical and computer engineering from Old Dominion University in 2014 and his B.S. in computer engineering from CNU in 2004.

\section{Dr. Anton Riedl, Christopher Newport University}

Dr. Anton Riedl is an Associate Professor of computer engineering at Christopher Newport University and currently the Chair of the Department of Physics, Computer Science and Engineering. Over the past 12 years he has taught a wide range of courses in computer engineering as well as computer science, including, among others, Engineering Design, Data Communications, and Cryptography/Network Security. His research interests are in computer and communication networking, as well as in unmanned autonomous systems. Dr. Riedl received the M.S. in Electrical Engineering from Purdue University and the Dipl.-Ing. and Dr.-Ing. in Electrical Engineering and Information Technology from Munich University of Technology, Germany.

\section{Dr. C. Gerousis, Christopher Newport University}

Costa Gerousis received the B.S., M.S., and Ph.D degree in electrical engineering from Arizona State University in 1994, 1996, and 2002 respectively. His post-doctoral appointment was from 2002 to 2003 with Nano-Research Group, Dept. of Electrical and Computer Engineering at Arizona State University. He joined in 2003 the faculty of Physics, Computer Science and Engineering at Christopher Newport University. His current research interest include nano-devices and architectures and robotics in education.

\section{Dr. Dali Wang, Christopher Newport University}

Dali Wang received his Ph.D. degree in electrical engineering from Florida Atlantic University, Boca Raton, FL. He is currently an associate professor in the Department of Physics, Computer Science and Engineering at Christopher Newport University. His research interests include digital signal processing, artificial intelligence, control and robotics. 


\title{
Improving Student Retention Through a Redesigned First-Year Engineering Class and Reshaping the Freshman Experience
}

\begin{abstract}
As a small engineering program at a liberal arts institution, we historically experienced low retention rates for our computer engineering (CE) majors. Consequently, we redesigned our introduction to engineering course as an effort to improve retention rate. Firstly, we decided to move the course from the sophomore to the freshman year to help the incoming cohort form a sense of community early on. Then we switched to having full time faculty become the primary instructors in order to increase connections with students. Most significantly, we completely redesigned the content and structure of the course. It used to be a traditional lecture-based course with an emphasis on technical aspects of design and engineering. However, after the change it became an activity driven, student-centric class with focus on active learning to engage students. Students now work on several team-based projects during the semester, which allows various aspects of engineering - problem solving, design, engineering standards, and social considerations - to be grasped in the process. Throughout the semester, there are several design competitions that draw spectators from all disciplines. These competitions teach students something beyond the subjects while being fun at the same time. We intend to use the class as a way for engineering students to build their own community and establish their own identity. We noticed students working in groups in this class tend to stick together afterwards in study groups, which contributed to their success in other classes. In addition to team building, we view the engineering design course as a "career molding" experience by showing the exciting, hand-on side of engineering. We believe all of these aspects contribute to the improvement of student retention rates.
\end{abstract}

In this paper, we will address the motivation for redesigning our engineering experience for first year students and re-shuffling of the CE 4-year plan based on observations and student retention rates. Then we will include descriptions of the newly designed first year engineering course, with detailed information about our team-based projects. We will discuss both benefits and potential pitfalls of this restructuring. Finally, retention data and trends will be discussed with some conclusions.

\section{Introduction}

Engineering programs at universities and colleges across the country are faced with increasing demands for high quality engineering graduates to meet the government's goal of producing one million new STEM graduates by $2022^{1}$. In support of this goal, the National Science Foundation has budgeted \$135 million for 2016 to support the retention of STEM students ${ }^{2}$ with additional support coming at the state and university level. This recent attention to STEM graduates and retention rates follows a long decline in interest among undergraduates in these technical fields ${ }^{3}$. Engineering programs are challenged with attracting more students to their programs while also keeping them from switching to other majors.

Research has shown that less than $60 \%$ of students who declare engineering as their major going into college graduate with that degree ${ }^{4}$. These low retention rates in engineering can be caused by several factors including gender, parental income, first-generation college student status, self- 
efficacy and high school experience and academic preparedness ${ }^{5}$. Although engineering programs may be unable to simultaneously address all of these problems, many have attempted novel ideas to improve retention rates. These include peer tutoring, learning communities, faculty mentoring, scholarships, summer programs, improved academic advising, research with faculty, integration with industry, engineering learning communities and many more ${ }^{6}$. One consensus resulting from this research is the importance of the First-Year Engineering Experience (FYEE) ${ }^{7}$. These FYEE programs have been proven to improve retention in a variety of universities. Common themes are building student community, a hands on teaching style, and faculty interaction.

A popular approach to the first-year experience has been to develop a first-year engineering course with a focus on activities to improve retention instead of exclusively on technical content. These course are becoming prevalent at many engineering programs and vary widely in implementation. Common approaches include providing students with hands-on experiences ${ }^{8}$, introducing students to industry professionals ${ }^{10}$, and focusing on under-performing demographics ${ }^{5}$.

As a small public liberal arts university, Christopher Newport University prides itself in personal attention and student engagement. The CE program is housed in the Department of Physics, Computer Science and Engineering (PCSE), and CNU first advertised the existence of the CE degree in Fall of 1994. The CE major, ABET accredited since 1997, has built a strong reputation across Virginia for producing graduates on par with the larger, more recognized universities. However, there was considerable room for improvement as for many years we had observed a low graduation rate for CE majors. The national statistics at the time showed that only about half of freshmen majoring in engineering go on to graduate with an engineering degree within six years. At CNU, our numbers were even lower with incoming freshman classes averaging nearly 30 students but with only about 10 graduates receiving engineering degrees each year.

In 2010 the Computer Engineering faculty set out to identify areas in our program that could be improved to increase the graduation rate. Since it has been widely shown that freshman to sophomore retention rates can be a great indicator of graduation rates, the faculty analyzed the year-to-year retention rates from 2002 to 2009. The study revealed that we were losing about half of a CE cohort during their freshman year. This data in Figure 1 are the first-to-second year retention rates during the time of the evaluation, i.e., the fraction of computer engineering freshmen that continued with the CE major in their second year. After seeing this data, the faculty decided that improving retention in the student's first year would provide the most direct method of increasing our overall graduation rate.

After a more in-depth look at the 2008 and 2009 freshmen who did not continue on to their sophomore years, two observations were made. First, the majority of students who dropped out of the Computer Engineering major stayed within the PCSE and switched instead to the Computer Science (CS) major. The faculty were pleased to learn that the CE dropouts did not leave the university and were not surprised at the switch due to the similarities in the majors. The main difference between the two majors during the first two years was that CS students did not have to start the Calculus sequence in their first semester and that they had a 100 level Physics (non-calculus) requirement instead of CE’s 200 level Physics (calculus based). 
Figure 1: First to Second Year Retention Rates in Computer Engineering

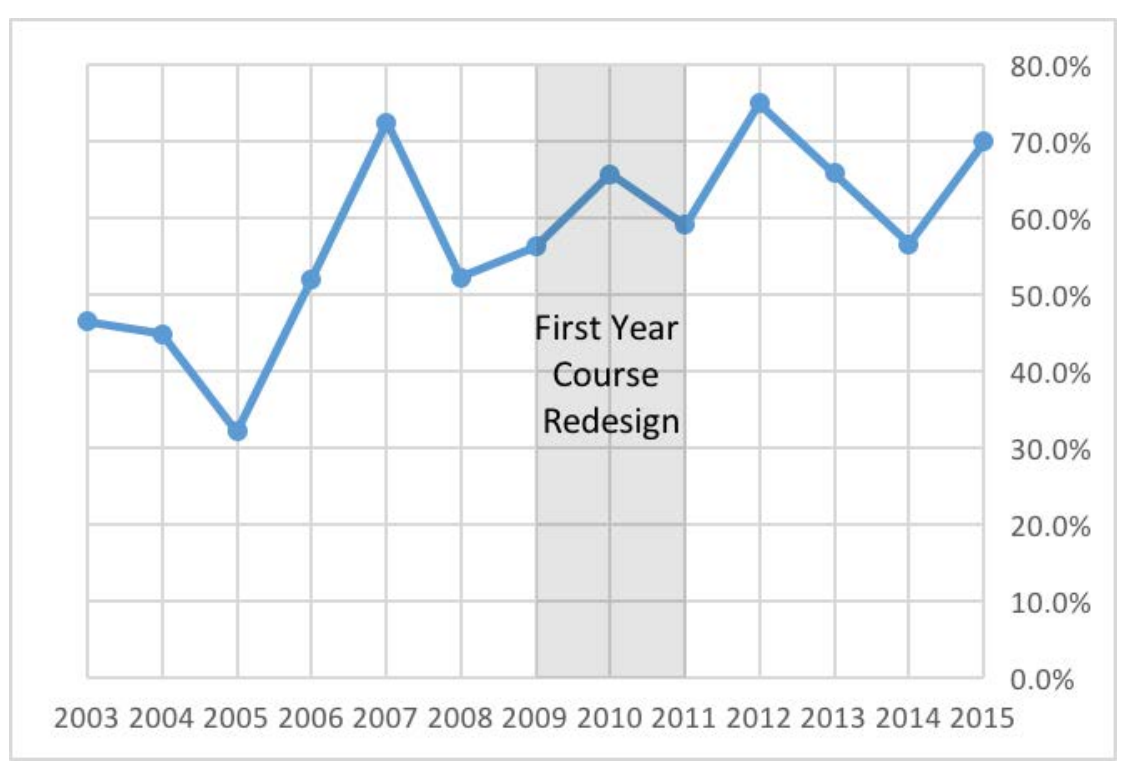

The second observation gave more insight into practical steps into improving retention. Specifically, the faculty was surprised to learn how many of the CE dropouts had failed one or more of the following three core technical classes: Physics, Calculus, and Computer Science. Figure 2 shows the fraction of first-year dropouts who failed these specific classes. Overall, almost $80 \%$ of dropouts had failed at least two of these classes. This was an alarming number and very concerning since these courses were typically not taught by Computer Engineering faculty. It was possible then for students to leave the major without having meaningful interaction with the program's faculty. Also this helped rationalize why so many of the CE dropouts ended up in CS. They continued to be interested in the computing field, but looked to take a lighter academic load. The faculty decided that increasing retention would in part require rethinking the current first year CE course requirements.

At the time, the four-year plan required Computer Engineering majors to take a combination of one calculus ( 4 credits), one physics (combined with lab, 4 credits), and one computer science (3 or 4 credits) course in each of their freshman semesters. Together with a general freshman seminar and a first-year writing class, this made for a very demanding first-year schedule, which was further complicated by the challenges that many students face as they transition from high school into college. Ultimately, it led to failed courses for a significant number of our majors. 
Figure 2: Percentage of First Year Drop-outs Who Failed a Core Class

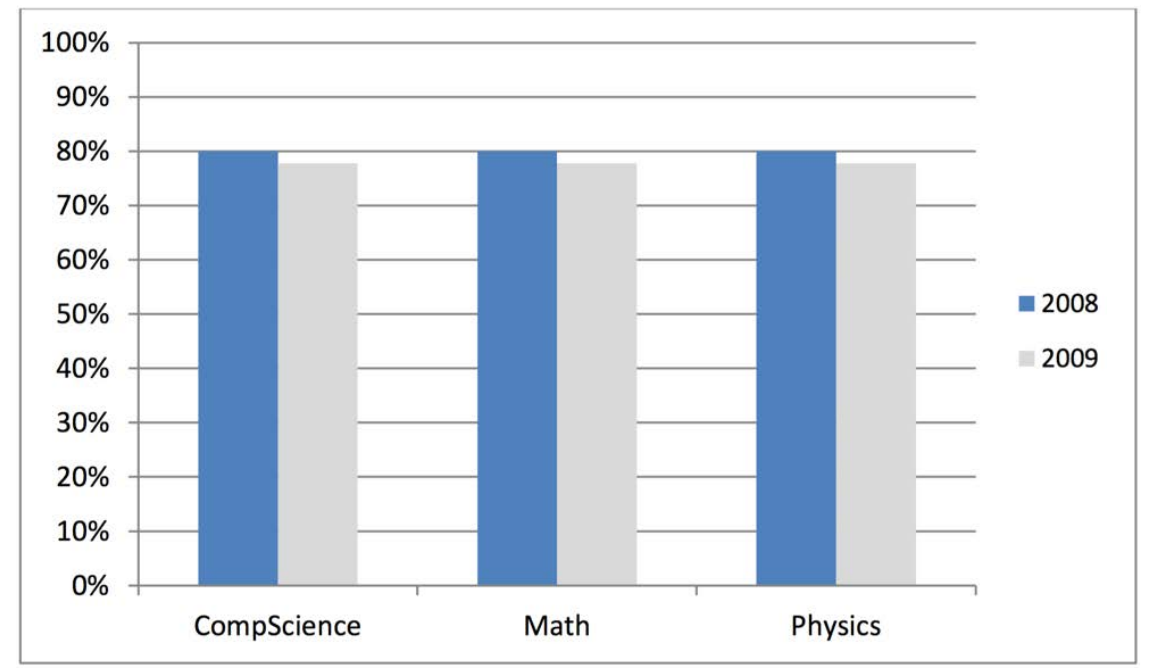

\section{Redesigning the First Year Engineering Class and Reshaping the Freshman Experience}

The effort to improve retention focused on alleviating three problematic aspects faced by first year engineering students. First, to address rates of failure in core classes during the freshman year, the four-year plan was redesigned by moving physics into the third semester. The overall requirements for a major in $\mathrm{CE}$ were not changed, but instead the heavy technical load was moved from first year to second year with this reshuffling. Since the introductory physics sequence is the prerequisite to many of the upper level courses in electronics, several additional courses had to be rearranged in the junior and senior years. As a result, the intensity of the course load in the first year was reduced giving freshmen more time to adjust to life on campus. Secondly, to help increase faculty-student interaction in the first year, it was decided to move the Engineering Design course (ENGR121) from the third into the first semester and have it be taught exclusively by full-time engineering faculty. Previously it had been taught by an adjunct professor. This would allow the computer engineering faculty to quickly build personal connections with incoming students from their first days on campus. Research has shown that the most rewarding experience for undergraduate students is doing meaningful work with faculty.

The third and primary area of focus was on redesigning this first-year ENGR 121 course to focus more on basic design principles and considerations, instead of mathematics and models. The class was restructured to comprise several design projects and one design competition at the end of the semester. Emphasis was placed on creating a very interactive and hands-on class, which offers many bonding opportunities for new engineering students.

The newly designed course had a more topical flow including the following areas designed to give students exposure to important topics for engineers that are rarely found in a purely technical course: 
- What is Engineering?

- The Engineering Design Process

- Learning to Present Technical Ideas

- Writing Professional Emails

- Successful Teamwork and Project Management

- Engineering Ethics

- Importance of Internships and Coops

Roughly one week of the course was dedicated to each of these topics. In addition to these, students were given five hands-on team projects throughout the semester to help reinforce several of these ideas. Examples of these included

- Marshmallow Challenge: emphasizing collaboration and importance of team dynamics

- Ping-Pong Launcher: emphasizing teamwork and the fun of engineering

- Rube Goldberg Machines: emphasizing creativity, fun and prototyping the design

- Lego NXT challenge 1: Programming, design and prototyping

- Lego NXT challenge 2: Programming, design, prototyping, writing and oral communication.

In particular, the inclusion of the Lego NXT platform using the RobotC language and development environment took fundamental computer programming technical concepts and made them very enjoyable to learn.

Students' reactions to the new hand-on approach were gauged using a combination of informal feedback and university standard student evaluations (IDEAs). Responses showed that students clearly enjoyed the opportunity to work together to develop creative solutions and were positive about faculty interaction. More focused surveys will be needed in the future to identify which of the changes in the first year experience was the most impactful. However, the overall outcome was viewed very positively from the students' perspective and had a positive effect on retention as will be discussed in following section.

Although the outcomes of the department's efforts to improve the first year experience were positive, the techniques used to redesign the freshman experience have been used in other universities. With so many engineering programs trying to increase retention, best practices are starting to become widely accepted ${ }^{6}$. The uniqueness of our approach is the application of our interventions at a small liberal arts college with a growing population of first generation engineers. Hopefully this study will give insight into the benefits of increasing faculty and student interaction in conjunction with hand-on activities.

\section{Impacts on Retention and Graduation}

Since the change in course structure and the redesign of ENGR 121, the effects on first to second year retention of our Computer Engineering majors has been noticeable. As shown in Figure 1 between 2009 and 2010 when the changes were initiated, the retention rates began to improve. There is some fluctuation in these rates due to the small sample size (freshman class again only about 30 students), however the trend has shown overall improvements. The 2014 low retention 
rate is seen as an aberration due to a well below average freshman class the previous year (23 students of whom 13 continued to sophomore year).

Figure 3: Computer Engineering Graduates at CNU

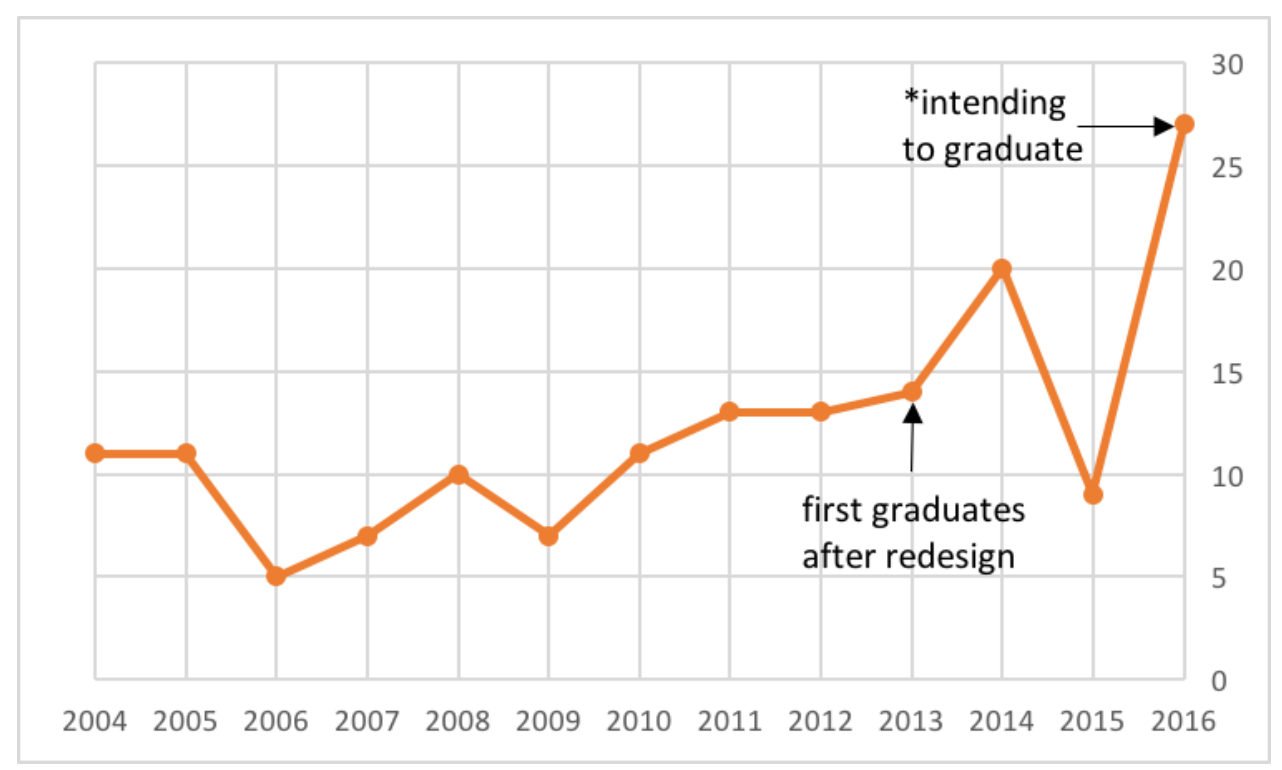

Consequently, the graduation rate for Computer Engineering majors has also increased significantly. Although we will not get our 6-year graduation rates for a few months, we are estimating that it has risen to over $45 \%$. This would be over a $15 \%$ increase since we redesigned the freshman engineering course in 2010. This is also reflected in the overall number of graduates as shown in Figure 3, with the trend steadily increasing. The aberration in year 2015 is caused by several students' decision to stay a semester longer in order to complete a second major. Thus the data from year 2015 should be looked together with the data from year 2016. The overall retention rate (from freshmen to senior) has thus risen to be on par with the national average for engineering majors.

\section{Conclusions}

Early results from retention data and graduation rates have shown that reorganizing first-year engineering students' experience and redesigning the first-year introduction to engineering course have had a positive impact on our students' attitude toward the engineering discipline. Students had more fun with the new hands-on project based course and a smoother transition to college with the reduced technical emphasis of freshman year courses. Overall, the faculty have noticed an improved freshman experience, and improvements in retention and graduation are beginning to be seen.

\section{Future Plans}

There are two very large state schools with wide-ranging engineering programs within 60 minutes of our campus at Christopher Newport University. With our university's emphasis on liberal arts and its small engineering student population, our faculty have noticed that many of 
the incoming freshman engineering students do not really understand what engineering is and thus have a weaker commitment to the program. Many of our students are merely directed towards engineering because of parents or advisors that saw skills in Math and Science at a high school level, however, they lack a personal commitment. Thus students are more likely to switch majors at the first obstacle (such as a failing grade). Therefore, we have begun to include a student success project based on the book Studying Engineering: A Road Map to a Rewarding Career by Ray Landis. This approach has shown improvement in first year retention at many engineering programs across the country, and we expect that it will have similar effects in our program.

\section{Bibliography}

1. President's Council of Advisors on Science and Technology, "Engage to Excel: Producing One Million Additional College Graduates with Degrees in Science, Tehcnology, Engineering, and Mathematics," Executive Office of the President, Washington D.C., 2012.

2. White House Office of Science and Technology Policy, "www.whitehouse.gov/ostp," February 2015. [Online]. Available: https://www.whitehouse.gov/sites/default/files/microsites/ostp/stem_fact_sheet_2016_budget_0.pdf. [Accessed 30 January 2016].

3. E. Seymore and N. Hewitt, Talking About Leaving: Why Undergraduates Leave the Sciences, Boulder: Westview Press, 1997.

4. U.S. Department of Education, "STEM Attrition: College Students' Paths Into and Out of STEM Fields," National Center for Education Statistics, Washngton DC, 2014.

5. E. Shaw and S. Barbuti, "Patterns of Persistence in Intended College Major with a Focus on STEM Majors," NACADA, vol. 30, no. 2, pp. 19-34, 2010.

6. American Society of Engineering Educators, "Going the Distance: Best Practices and Strategies for Retaining Engineering, Engineering Technology and Computing Students," ASEE, Washington DC, 2012.

7. R. Sprang and S. Strom, "Improving Freshman Retention in an Engineering Technology Program," in 122nd ASEE Annual Conference \& Exposition, Seattle, 2015.

8. G. Bucks, K. Ossman, J. Kastner, J. Boerio and J. Torsella, "First Year Engineering Courses Effect on Retention and Student Engagement," in 121st ASEE Annual Conference \& Exposition, Indianapolis, 2014.

9. G. Bucks, K. Ossman, J. Kastner and J. Boerio, "First-Year Engineering Courese Effect on Retention and Workplace Performance," in 122nd ASEE Annual Conference \& Exposition, Seattle, 2015.

10. P. Sable, S. Karackattu and M. Traum, "First-Year Student Persistence and Retention Influenced by Early Exposure to Engineering Practitioners Co-Teaching Entry-Level Courses: A Four-Year Indirect Assessment," in 121st ASEE Annual Conference \& Exposition, Indianapolis, 2014.

11. S. Steadman, G. Jefferson, T. Thomas and K.-T. Hsiao, "Impacting First year Engineering Retention," in 121st ASEE Annual Conference \& Exposition, Indianapolis, 2014. 